\title{
Workplace bullying and sickness absence in hospital staff
}

\author{
Mika Kivimäki, Marko Elovainio, Jussi Vahtera
}

\begin{abstract}
Objectives-In the past, evidence on the negative consequences of workplace bullying has been limited to cross sectional studies of self reported bullying. In this study, these consequences were examined prospectively by focusing on sickness absence in hospital staff.
\end{abstract}

Methods-The Poisson regression analyses of medically certified spells ( $\geqslant 4$ days) and self certified spells (1-3 days) of sickness absence, relating to bullying and other predictors of health, were based on a cohort of 674 male and 4981 female hospital employees aged 19-63 years. Data on sickness absence were gathered from employers' registers. Bullying and other predictors of health were measured by a questionnaire survey.

Results-302 (5\%) of the employees reported being victims of bullying. They did not differ from the other employees in terms of sex, age, occupation, type of job contract, hours of work, income, smoking, alcohol consumption, or physical activity. Victims of bullying had higher body mass and prevalence of chronic disease, and their rates of medically and self certified spells of sickness absence were $1.5(95 \%$ confidence interval (95\% CI) 1.3 to 1.7$)$ and $1.2(1.1$ to 1.4$)$ times higher than those of the rest of the staff. The rate ratios remained significant after adjustment for demographic data, occupational background, behaviour involving risks to health, baseline health status, and sickness absence.

Conclusion-Workplace bullying is associated with an increase in the sickness absenteeism of the hospital staff. Targets of bullying seem not to belong to any distinct group with certain demographic characteristics or occupational background.

(Occup Environ Med 2000;57:656-660)

Keywords: workplace bullying; sickness absence; health; psychosocial factors; hospital staff

Workplace bullying is claimed to be a serious problem in modern working life, including healthcare organisations. ${ }^{12}$ Although a generally accepted definition of bullying is still lacking, ${ }^{2}$ it often refers to situations in which someone is subjected to social isolation or exclusion, his or her work and efforts are devalued, and he or she is threatened or otherwise worn down or frustrated. In a random sample of Finnish citizens aged 25-64, 4\% of workers in social welfare and healthcare reported being victims of bullying. ${ }^{3}$ The corresponding range in Norwegian samples of healthcare workers was $3 \%-8 \%,{ }^{4-6}$ and $8 \%$ of employees in a sample of workers in an Austrian hospital and research institute were bullied. ${ }^{7}$ Almost $40 \%$ of employees reported experiences of bullying when a broader definition was used in a study on a British National Health Service Community Trust. ${ }^{2}$

Bullying in hospitals and other healthcare organisations has been associated with self reported burn out, psychological and somatic complaints, ${ }^{4}$ dissatisfaction, ${ }^{8}$ anxiety, depression, job dissatisfaction, job stress, and the propensity to leave. ${ }^{2}$ It has also been claimed that employees other than victims were negatively affected in work units where bullying exists. ${ }^{9}$

To complement the previous evidence of the potential negative influences of bullying, we investigated whether bullying in hospitals is associated with records of staff sickness absence. Sickness absence is a well defined outcome and important as a measure of ill health, the use of health services, and as a reason for lost productivity.

\section{Methods}

STUDY CONTEXT AND PARTICIPANTS

In Finland, each municipality, alone or jointly with other municipalities, organises hospital care for its inhabitants. This study was carried out in two hospital districts (Varsinais-Suomi and Kanta-Häme) participating in a project "Work and health in Finnish hospital personnel" coordinated by the Finnish Institute of Occupational Health. There was one university teaching hospital, one central hospital, and eight regional hospitals. These hospitals provided specialised care for 614000 inhabitants ( $12 \%$ of the total Finnish population).

Approval of the ethics committee of the Finnish Institute of Occupational Health was obtained for the study. We used employers' records to identify all hospital staff with a job contract covering 14 days or more in the service of these hospitals at the beginning of 1998 . There were 7375 employees (1156 men, 6219 women) working in 334 work units. We sent these employees a self administered questionnaire containing questions about bullying, behavioural health risks, and health status. Assuming a type I error rate of 0.05 , a response rate of $70 \%$, and a prevalence of bullying of $5 \%$, this sample size would have $90 \%$ power to detect a difference of $10 \%(60 \% v 70 \%)$ in the annual incidence of sickness absence between victims of bullying and other employees. ${ }^{10}$ 
Table 1 Characteristics of the participants

\begin{tabular}{|c|c|c|c|c|}
\hline Characteristics & $\begin{array}{l}\text { Bullied }(n=302) \\
n(\%)\end{array}$ & $\begin{array}{l}\text { Not bullied } \\
(n=5353) \\
n(\%)\end{array}$ & $\chi^{2}$ & $p$ Value \\
\hline Sex: & & & 0.0 & NS \\
\hline Men & $35(12)$ & $639(12)$ & & \\
\hline Women & $267(88)$ & $4714(88)$ & & \\
\hline Age (y): & & & 6.4 & NS \\
\hline $18-30$ & $20(7)$ & $524(10)$ & & \\
\hline $31-40$ & $71(24)$ & $1449(27)$ & & \\
\hline $41-50$ & $119(39)$ & $1880(35)$ & & \\
\hline$>50$ & $92(30)$ & $1500(28)$ & & \\
\hline Occupational group: & & & 3.3 & NS \\
\hline Doctors & $24(8)$ & $375(7)$ & & \\
\hline Nurses & $149(50)$ & $2670(50)$ & & \\
\hline Other professionals & $11(4)$ & $198(4)$ & & \\
\hline Laboratory and $x$ ray staff & $33(11)$ & $729(14)$ & & \\
\hline Administrative staff & $34(11)$ & $631(12)$ & & \\
\hline Maintenance, cleaning, etc & $50(17)$ & $749(14)$ & & \\
\hline Job contract: & & & 0.2 & NS \\
\hline Permanent & $238(79)$ & $4143(78)$ & & \\
\hline Temporary & $64(21)$ & $1192(22)$ & & \\
\hline Hours of work: & & & 0.1 & NS \\
\hline Full time & $281(95)$ & $4961(94)$ & & \\
\hline Part time & $16(5)$ & $302(6)$ & & \\
\hline Income (quartiles) ${ }^{\star}$ : & & & 0.6 & NS \\
\hline 1 & $96(32)$ & $1614(30)$ & & \\
\hline 2 & $77(26)$ & $1408(26)$ & & \\
\hline 3 & $67(22)$ & $1265(24)$ & & \\
\hline 4 & $62(21)$ & $1066(20)$ & & \\
\hline Smoking: & & & 1.2 & NS \\
\hline Non-smoker & $209(72)$ & $3590(70)$ & & \\
\hline Former smoker & $45(16)$ & 745 (15) & & \\
\hline Current smoker & $37(13)$ & $769(15)$ & & \\
\hline Alcohol consumption $\dagger$ : & & & 0.2 & NS \\
\hline Low & $138(46)$ & $2492(47)$ & & \\
\hline Medium & $134(44)$ & $2365(44)$ & & \\
\hline High & $30(10)$ & $496(9)$ & & \\
\hline Physical activity: & & & 0.9 & NS \\
\hline Sedentary & $72(24)$ & $1158(22)$ & & \\
\hline Non-sedentary & $230(76)$ & $4195(78)$ & & \\
\hline Body mass index $\left(\mathrm{kg} / \mathrm{m}^{2}\right)$ : & & & 8.3 & .016 \\
\hline$\leqslant 20$ & $32(11)$ & $489(9)$ & & \\
\hline $20-30$ & $230(76)$ & $4395(82)$ & & \\
\hline$>30$ & 40 (13) & $469(9)$ & & \\
\hline Diagnosed chronic disease: & & & 33.6 & $<.001$ \\
\hline No & $102(34)$ & $2726(51)$ & & \\
\hline Yes & $200(66)$ & $2627(49)$ & & \\
\hline
\end{tabular}

^In men, cut off points for quartiles were 9911 FIM, 11491 FIM, and 22991 FIM per month; and in women were 8584 FIM, 10298 FIM, and 10972 FIM per month.

†In men, low (<40 g absolute alcohol/week), medium (40-280 g/week), high ( $>280 \mathrm{~g} /$ week) in women, low (<40 g absolute alcohol/week), medium (40-190 g/week), high ( $>190 \mathrm{~g} / \mathrm{week})$.

Five thousand, six hundred and fifty five (77\%) employees (674 men, 4981 women) responded to the questionnaire. The mean (SD) age was 43.7 (9.2) years, $7 \%$ were physicians, $50 \%$ nurses, $4 \%$ other professionals, $13 \%$ laboratory and $x$ ray staff, $12 \%$ administrative staff, and $14 \%$ worked in maintenance, cleaning, and other activities. Most of the respondents had a permanent job contract $(78 \%)$ and a full time job $(94 \%)$.

Sample attrition was selective, being greater among the men $(42 \%)$ than among the women $\left(20 \%, \chi^{2}=258.8, p<0.001\right)$, in employees with a temporary job $(30 \%)$ than in those with a permanent job $\left(21 \%, \chi^{2}=68.4, p<0.001\right)$, and in doctors $(47 \%)$ than in nurses $(17 \%)$, other professionals $(19 \%)$, laboratory and $x$ ray staff $(25 \%)$, administrative staff $(23 \%)$, or other personnel $\left(27 \%, \chi^{2}=319.4, p<0.001\right)$. Other differences between the participants and those who refused to participate were mean age (42.5 $v 43.7$ years, $F=22.1, \mathrm{p}<0.001)$ and income (12234 v 10934 FIMs per month, $F=133.6$, $\mathrm{p}<0.001)$.

MEASURES

Bullying was measured by the following question: "Workplace bullying refers to a situa- tion where someone is subjected to social isolation or exclusion, his or her work and efforts are devalued, he or she is threatened, derogatory comments about him or her are said behind his or her back, or other negative behaviour aimed to torment, wear down, or frustrate occur. Have you been subjected to such bullying behaviours?" (from the standard survey by Statistics Finland). ${ }^{11}$ The victims were recorded by a rating "Yes, currently" and non-victims by the other ratings ("Yes, previously at my present workplace, but not anymore"; "Yes, previously in another workplace, but not anymore"; "No"; and "I don't know"). ${ }^{11}$ There were 302 victims (35 men and 267 women).

Smoking was assessed by means of a question about whether the respondent was a nonsmoker $(n=3799)$, a former smoker $(n=790)$, or a current smoker $(n=806)$. Assessment of absolute alcohol (g) consumed in an average week (mean (SD) 78.0 (105.9)) was based on an alcohol questionnaire by Kaprio et al. ${ }^{12} \mathrm{~A}$ sedentary lifestyle was indicated by leisure time physical activity corresponding to under half an hour of fast walking a week (1230 were sedentary, 4425 not)..$^{13}$ Body mass index was calculated from information on weight and height (mean (SD) 24.6 (3.9)). A measure of a diagnosed disease (yes or no) was derived from the responses on a list of 14 chronic diseases diagnosed by a doctor-for example, asthma, rheumatoid arthritis, osteoarthritis, sciatica, diabetes, cardiovascular disease- and an open question about chronic diseases not included in the list (2828 had a chronic disease, 2827 had not). ${ }^{14}$

We obtained information on the participants' occupational title, work unit, contracted days, and sickness absence from the employers' registers. Occupational titles, expressed in five digit Statistics Finland (official Finnish government statistics) codes, were used to link information on income to the data set. Mean (SD) monthly income figures, calculated separately for men and women by occupational title, were obtained from Statistics Finland (10 934 (3581) FIM).

The sickness absence registers documented each period of sick leave for every employee, giving the beginning and end dates of each spell. In accordance with the regulations, each sick leave certificate, irrespective of the place of issue, must be forwarded to these registers. In the case of short spells ( 3 days or less), employees inform their supervisor on the morning of the first day of absence and fill out their own certificate explaining their absence. For long spells (more than 3 days), a physician's examination on the 4 th day of absence, at the latest, and a medical certificate covering the entire period of sickness absence are required. Reasons for sickness absence are coded according to the international classification of diseases, 1993 revision. ${ }^{15}$ Maternity leave and absences due to caring for a sick child are not included in the sickness absences.

All of the participants' sickness absences between 1 January 1997 and 31 December 1998 , were obtained from the registers. Overlapping, consecutive, or duplicated spells were 
Table 2 Medically certified and self certified sickness absences of victims of bullying and of other employees

\begin{tabular}{|c|c|c|c|c|c|c|}
\hline & & $\begin{array}{l}\text { Absence rate per } 100 \\
\text { person-years }\end{array}$ & $\begin{array}{l}\text { Model I Rate ratio } \\
(95 \% \text { CI })\end{array}$ & $\begin{array}{l}\text { Model II Rate ratio } \\
(95 \% \text { CI) }\end{array}$ & $\begin{array}{l}\text { Model III Rate ratio } \\
(95 \% \text { CI })\end{array}$ & $\begin{array}{l}\text { Model IV Rate ratio } \\
(95 \% \text { CI) }\end{array}$ \\
\hline \multicolumn{7}{|c|}{ Medically certified sickness absence: } \\
\hline Not bullied $(n=5353)$ & 4414 & 69.3 & 1.00 & 1.00 & 1.00 & 1.00 \\
\hline Bullied $(\mathrm{n}=302)$ & 248 & 105.5 & $1.51(1.31$ to 1.72$)$ & $1.46(1.28$ to 1.66$)$ & $1.36(1.19$ to 1.58$)$ & $1.26(1.10$ to 1.44$)$ \\
\hline \multicolumn{7}{|c|}{ Self certified sickness absence: } \\
\hline Not bullied $(n=5353)$ & 4414 & 146.3 & 1.00 & 1.00 & 1.00 & 1.00 \\
\hline Bullied $(n=302)$ & 248 & 177.0 & $1.23(1.12$ to 1.36$)$ & $1.23(1.11$ to 1.35$)$ & $1.21(1.09$ to 1.34$)$ & $1.16(1.05$ to 1.29$)$ \\
\hline
\end{tabular}

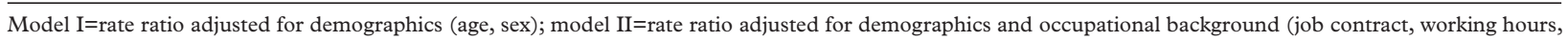
income); model III=rate ratio adjusted for demographics, occupational background, behavioural risks, and health status (smoking, pack-years, alcohol consumption, sedentariness, body mass index, and diagnosed chronic diseases); model IV=rate ratio adjusted for demographics, occupational background, behavioural risks, health status, and baseline sickness absence.

merged. Sickness absences were divided into medically certified spells of sickness absence (spells of 4 days or more) and self certified spells of sickness absence (spells of 3 days or fewer). The follow up time for spells of absence was the number of contracted days worked.

Medically certified and self certified spells per contracted days worked in 1997 were used as a measure of baseline sickness absence. Sickness absence in 1998 was the dependent variable.

\section{STATISTICAL METHODS}

We measured the rates of sickness absence for victims versus non-victims of bullying, and for non-victims working in units where bullying exists versus non-victims in other work units and the corresponding rate ratios $(95 \%$ confidence intervals (95\% CIs)) by Poisson regression analysis. ${ }^{16-18}$ The dispersion in medically certified and self certified spells of sickness absence followed the assumptions for Poisson models. We adjusted the rate ratios for demographic characteristics, occupational background, behavioural risks, chronic diseases, and sickness absence at the baseline. Interaction terms were applied to test whether the associations between bullying and sickness absence were dependent on sex, age, job contract, hours of work, income, smoking, alcohol consumption, sedentariness, body mass index, or diagnosed diseases. ${ }^{19}$

\section{Results}

Five per cent of the participants reported experiences of bullying. The victims of bullying did not differ from the other employees for sex, age, occupational background, or health habits such as smoking, alcohol consumption, or physical activity. The victims more often had a chronic disease. They also had a slightly higher body mass index (table 1).

SICKNESS ABSENCE IN VICTIMS OF BULLYING

The rate medically certified sickness absence adjusted for age and sex was $51 \%$ greater in the victims of bullying than among the other employees. The corresponding difference in the rates of self certified sickness absence was $23 \%$ (table 2).

To estimate the extent to which bullying increased the risk of sickness absence, the rate ratios were adjusted for baseline sickness absence (rate of sick leave 1 year before the survey) as well as the other covariates. In the fully adjusted model, the risk of medically certified sickness absence was $26 \%$ greater in the victims than among the others. The corresponding percentage of self certified sickness absence was $16 \%$ (table 2).

The analyses of the interactions showed that the associations of bullying with medically certified and self certified sickness absence were not dependent on demographic characteristics (sex, age, job contract, hours of work, and income), health risk behaviour (smoking, alcohol consumption, sedentariness, body mass index), or baseline health.

\section{SICKNESS ABSENCE IN EMPLOYEES WORKING IN} UNITS WHERE BULLYING EXISTS

Of the 5353 employees who were not bullied, $3167(59 \%)$ worked in organisational units where at least one of the employees reported experience of bullying. The rate of medically certified sickness absence was $9 \%$ higher in the non-victims working in units in which bullying occurred than that in other non-victims. However, the rate ratio did not remain significant after adjustment for baseline sickness absence. No differences in self certified sickness absences were found between the employees working in the units with bullying and those working in other units (table 3 ).

\section{Discussion}

We found that $5 \%$ of the participants experienced bullying. This prevalence can be compared with the rate of $4 \%$ in a national survey of the workforce ${ }^{3}$ and prevalences between 3\% and $8 \%$ reported in several other studies of

Table 3 Medically certified and self certified sickness absences of non-victims at work units in which bullying exists and in other work units

\begin{tabular}{|c|c|c|c|c|c|c|}
\hline Employees working & $\begin{array}{l}\text { Person- } \\
\text { years }\end{array}$ & $\begin{array}{l}\text { Absence rate per } \\
100 \text { person-years }\end{array}$ & $\begin{array}{l}\text { Model I rate ratio } \\
(95 \% \text { CI) }\end{array}$ & $\begin{array}{l}\text { Model II rate ratio } \\
(95 \% \text { CI })\end{array}$ & $\begin{array}{l}\text { Model III rate ratio } \\
(95 \% \text { CI) }\end{array}$ & $\begin{array}{l}\text { Model IV rate ratio } \\
(95 \% \text { CI) }\end{array}$ \\
\hline \multicolumn{7}{|l|}{ Medically certified sickness absence: } \\
\hline In work units with no bullying $(n=2186)$ & 1807 & 65.9 & 1.00 & 1.00 & 1.00 & 1.00 \\
\hline In units with bullying $(\mathrm{n}=3167)$ & 2607 & 71.7 & $1.09(1.02$ to 1.18$)$ & $1.09(1.01$ to 1.17$)$ & $1.06(0.98$ to 1.16$)$ & $1.03(0.95$ to 1.11$)$ \\
\hline \multicolumn{7}{|l|}{ Self certified sickness absence: } \\
\hline In work units with no bullying $(n=2186)$ & 1807 & 141.2 & 1.00 & 1.00 & 1.00 & 1.00 \\
\hline In units with bullying $(n=3167)$ & 2607 & 149.8 & $1.05(1.00$ to 1.10$)$ & $1.04(0.99$ to 1.09$)$ & $1.04(0.98$ to 1.10$)$ & $1.04(0.98$ to 1.10$)$ \\
\hline
\end{tabular}

Footnotes as for table 2 . 
healthcare personnel. ${ }^{4-7}$ The response rate in our survey was $77 \%$, which is highly satisfactory for studies of this kind. ${ }^{20}$ Although the sample was selective for demographic characteristics and occupational background, this probably did not bias the prevalence because there was no variation in these factors between the bullied and the other employees.

In the present study, workplace bullying was associated with an increase in sickness absence. This finding was expected on the basis of earlier cross sectional studies of self reported bullying $^{2489}$ and because problems in social relations have been thought to decrease a person's resistance through immunological and neuroendocrinological mechanisms. ${ }^{21}$ Workplace bullying includes elements of social conflict, isolation, and poor social support, all of which have been found to link with morbidity and mortality in prospective studies. ${ }^{22-24}$

It has been argued that serious interpersonal problems at work may have more negative consequences on a person than such problems outside work. ${ }^{25}$ Work is not only related to a basic adult obligation to provide for oneself and one's family, but is also assumed to be highly important in shaping people's self respect, self images, and identities. ${ }^{26}$ Our ratio of 1.5 in the rates of medically certified sickness absence between victims and non-victims of bullying was higher than or equal to the rate ratios reported in relation to poor social support and being exposed to low job control and high demands, ${ }^{27} 28$ all of which are well established psychosocial predictors of health and sickness absenteeism. ${ }^{17}{ }^{29-31}$

The process of bullying may include characteristics of the vicious circle in which poor health is a result of bullying and a factor increasing susceptibility to becoming a victim of bullying. To exclude the reverse effect of poor health on bullying, we adjusted the rate ratios for baseline absence, health risks, and health status. The risk of medically certified sickness absence also remained significantly higher in the victims of bullying than in the others. For at least two reasons, the observed rate ratio of 1.2 is probably an underestimation of the actual effect. Firstly, in some cases bullying could have begun long before the measurement of baseline absence and consequently adjustment led to overcontrol. Secondly, in line with many other studies, ${ }^{36}$ victims were recorded from a positive response to a global definition of bullying. The frequency and time of the exposure were not requested from the participants. ${ }^{3}$ The chance of finding associations with such a measure may be lower than with a more specific instrument to detect victims, which would rate a list of specific negative behaviours. ${ }^{2}$

Bullying was associated more strongly with medically certified sickness absence than with self certified sickness absence. Previous research suggests that medically certified absence is more accurate a measure of health than self certified absence, which may also reflect voluntary absenteeism. ${ }^{32} 33$ It has been argued that victims of bullying may exaggerate in portraying themselves as hard working people. ${ }^{3435}$
Thus, they may think it particularly important to minimise their self certified absences to avoid a stigma of malingering.

The absence rate of $4 \%$ of total contracted days found in our sample was equal to that found in employees of the British National Health Services Trusts. ${ }^{8}$ The immediate financial consequences of bullying relate to the costs that result from an increase in absenteeism. In our study, the number of lost days due to extra sick leave among victims was about $2 \%$ of all days of staff sickness absence. Including lost salaries, the annual cost of absence related to bullying was about FIM 1.2 million (about $£ 125000)$ in the hospitals studied. These calculations do not take into account the costs occurring as a result of lower motivation, social security claims, and impaired quality of patient care, or because a considerable percentage of victims decide to leave their employment as a result of the bullying process. ${ }^{34}$

We did not find any differences in demographic or occupational characteristics between the victims of bullying and the other employees. Such comparisons have led to mixed results in earlier studies. ${ }^{34}{ }^{36}$ It is likely that workplace bullying is a widespread form of interpersonal conflict and not a problem among a certain distinct occupational group. Potential risk groups for bullying may therefore be difficult to identify.

Several European countries, including Great Britain, Sweden, Norway, and Finland, have implemented general preventive actions against workplace bullying. ${ }^{26}$ These include for example, efforts to increase public awareness, funding for research into bullying by government, trade unions, and other organisations, and the establishment of antibullying programmes and legislation. Our analyses of hospital staff suggest that bullying is a problem with negative consequences. A reduction is not only likely to help the victims but also to bring economic benefits for employers.

MK coordinated the project, designed, checked, and collated the data, supervised the data analysis, and was the principal author of the paper. $\mathrm{ME}$ and $\mathrm{JV}$ helped in the data analysis, advised in the interpretation and presentation of the results, and contributed to the writing of the paper. The study was supported by grants from the Academy of Finland (project no 44 968), the Finnish Work Environment Fund (project no 97316 ), and the hospitals in the districts of Varsinais-Suomi and Kanta-Häme, Finland.

1 Kline R. Asking why and saying no. Health Visitor 1994; 67:359.

2 Quine L. Workplace bullying in NHS community trust: staff questionnaire survey. BMF 1999;318:288-32.

3 Kauppinen T, Aaltonen M, Lehtinen S, et al. Work and health in Finland 1997. Helsinki: Finnish Institute of Occupational Health, 1997.

4 Matthiessen SB, Raknes BI, Rokkum O. Mobbing på arbeidsplassen. Tidskrift för Norsk Psykologförening 1989:26; $761-74$

5 Skogstad A, Matthiesen SB, Hellesoy OH. Hjelpepleiernes arbeidsmiljökvalitet. En undersökelse av arbeidsmiliö, helse og trivsel blant hjelpepleierne $i$ Hordaland. Bergen: University of Bergen, 1990

6 Einarsen S, Skogstad A. Bullying at work: epidemiological indings in public and private organisations. European fournal of Work and Organizational Psychology 1996;5:185-201.

Niedl K. Mobbing/bullying am Arbeitsplatz. Munich: Rainer Hampp, 1995.

8 Frank E, McMurray JE, Linzer M, et al. Career satisfaction of US women physicians: results from the women physicians' health study. Arch Intern Med 1999;159:141726 .

9 Barker M, Sheehan M, Rayner C. Workplace bullying: perspectives on a manpower challenge. International fournal of Manpower 1999;20:8-9. 
10 Fleiss JL. Statistical methods for rates and proportions, 2nd ed. New York: Wiley, 1981.

11 Lehto A-M. Quality of working life and equity. Helsinki: Statistics Finland, 1991.

12 Kaprio J, Koskenvuo M, Langinvainio H, et al. Genetic influences on use and abuse of alcohol: a study of 5638 adult Finnish twin brothers. Alcohol Clin Exp Res 1987;11: 349-56.

13 Kujala UM, Kaprio J, Sarna S, et al. Relationship of leisuretime physical activity and mortality. $\mathcal{F} A M A$ 1998;279:4404.

14 Vahtera J, Uutela P, Pentti J. The effects of objective job demands on registered sickness absence spells: do personal, social and job-related resources act as moderators? Work Stress 1996;10:286-308.

15 World Health Organisation. International classification of diseases, 1993 revision. WHO: Geneva, 1993.

16 Vahtera J, Kivimäki M, Pentti J. Effect of downsizing on health of employees. Lancet 1997;350:1124-8.

17 Kivimäki M, Vahtera J, Pentti J, et al. Factors underlying the effect of organisational downsizing on health of employees: longitudinal cohort study. BMF 2000;319:971-5

18 SAS/STAT software. The genmod procedure, Release 6.09. Cary, NC: SAS Institute, 1993. (SAS Technical Report P-243.)

19 Cohen J, Cohen P. Applied multiple regression/correlation analysis for the behavioral sciences. Erlbaum, NJ: Hillsdale, 1983.

20 Nachmias C, Nachmias D. Research methods in the social science. New York: St Martin's Press, 1981.

21 Cassel J. The contribution of social environment to host resistance. Am f Epidemiol 1976;104:107-23.

22 House JS, Landis KR, Umberson D. Social relationships and health. Science 1988;241:540-5.

23 Vogt TM, Mullooly JP, Ernst D, et al. Social networks as predictors of ishemic heart disease, cancer, stroke and hypertension: incidence, survival and mortality. $\mathcal{F}$ Clin Epidemiol 1992;45:659-66.

24 Orth-Gomer K, Rosengren A, Wilhelmsen L. Lack of social support and incidence of coronary heart disease in middleaged Swedish men. Psychosom Med 1993;55:37-43.
25 Bolger N, DeLongis A, Kessler RC, et al. Effects of daily stress on negative mood. F Pers Soc Psychol 1989;57:80818

26 Einarsen S, Raknes BI. Harassment in the workplace and the victimization of men. Violence Vict 1997;12:247-63.

27 Kivimäki M, Vahtera J, Thomson L, et al. Psychosocial factors predicting employee sickness absence during economic decline. F Appl Psychol 1997;82:858-72.

28 Vahtera J, Kivimäki M, Pentti J, et al. Effect of change in the psychosocial work environment on sickness absence: a 7 year follow up of initially healthy employees. $\mathcal{F}$ Epidemiol Community Health 2000;54:484-93.

29 Johnson JV, Hall EM, Theorell T. Combined effects of job strain and social isolation on cardiovascular disease morbidity and mortality in a random sample of the Swedish male working population. Scand $\mathcal{F}$ Work Environ Health 1sh male workin
1989;6:271-9.

30 Karasek RA, Theorell T. Stress, productivity, and reconstruction of working life. New York: Basic Books, 1990.

31 Bosma $\mathrm{H}$, Marmot MG, Hemingway $\mathrm{H}$, et al. Low control and risk of coronary heart disease in Whitehall II (prospective cohort) study. BMF 1997;314:558-64.

32 Marmot MG, Feeney A, Shipley M, et al. Sickness absence as a measure of health status and functioning: from the UK Whitehall II study. F Epidemiol Community Health 1995;49: 124-30.

33 Hensing G, Alexanderson K, Allebeck P, et al. How to measure sickness absence? literature review and suggestion of five basic measures. Scand 7 Social Med 1998;26:133-44.

34 Hoel H, Rayner C, Cooper CL. Workplace bullying. International Review of Industrial and Organizational Psychology 1999;14:196-230.

35 Zapf D. Organizational, work group related and personal causes of mobbing/bullying at work. Fournal of Manpower 1999;20:70-85.

36 Vartia $M$. The sources of bullying: psychological work environment and organizational climate. European fournal of Work and Organizational Psychology 1996;5:203-14.

\section{Open reviewing}

Many journals, including the BMJ, have moved to a system of open reviewing, whereby authors know the names of reviewers of their papers. Research has shown that named reviews, although not of better quality than anonymous reviews, are not of worse quality either. Therefore in the interests of transparency, it seems fair to let authors know who has reviewed their paper. At Occupational and Environmental Medicine we have considered the issue carefully. There are some concerns that reviewers, especially those who are more junior, might feel intimidated and not wish to make negative comments about papers submitted by senior people in the field. On the other hand, some reviewers might hide behind the cloak of anonymity to make unfair criticisms so as to reduce the chances of publication by rivals. We have decided to introduce initially a system of open reviewing if the reviewers agree explicitly. So when a reviewer is sent a paper, he or she is asked to indicate whether we can disclose their name or not when sending the authors their comments. We will be monitoring this to see how many of our reviewers are happy to be named. If it is most of them, we will move to a system of open reviewing as the norm, with a possible "opt out" clause for reviewers. 